\title{
Muscle colour development in Arctic charr, Salvelinus alpinus (L.), monitored by fibre-optics and electrical impedance
}

\author{
H J Swatland, F Darkin, S J Naylor, L Caston \& R D Moccia \\ Department of Animal \& Poultry Science, University of Guelph, Guelph, Ontario, Canada
}

Correspondence: H J Swatland, Department of Animal \& Poultry Science, University of Guelph, Guelph, Ontario, Canada N1G 2W1

\begin{abstract}
Farmed Arctic charr, Salvelinus alpinus (L.), $(n=270)$ with a wide range of carotenoid muscle pigmentation were produced by feeding astaxanthin at different levels (0-120 mg kg-1 feed). Steaks were scored subjectively for pigment concentration (dark $=$ high score $)$. Internal reflectance spectra were measured with a relatively non-destructive 1 mm-diameter fibre-optic probe. Colour scores were only moderately correlated with reflectance $(R=$ 0.66 and $P<0.01$, using data at 500, 610 and $520 \mathrm{~nm}$ ) because the small-diameter probe had a short light-path through the tissue and was highly responsive to scattering. However, in fish without astaxanthin in their diet, this sensitivity to microstructural causes of scattering revealed that fibre-optic reflectance increased $(P<0.01)$ with age from $400 \mathrm{~nm}(r=0.68)$ to $440 \mathrm{~nm}(r=0.40)$, and from $530 \mathrm{~nm}(r=0.30)$ to $700 \mathrm{~nm}(r=0.56)$. In agreement with these results, colour scores decreased with age $(r=-0.52 ; P<0.001 ; n=85)$, as did electrical resistance $24 \mathrm{~h}$ post-mortem $(r=-$ 0.42 at $120 \mathrm{~Hz}, r=-0.39$ at $1 \mathrm{kHz}$ and $r=-0.54$ at $10 \mathrm{kHz} ; P<0.001)$. Resistance was correlated with colour score $(r=0.40$ and $P<0.001$ for resistance at $10 \mathrm{kHz}$ ) and with fibre-optic reflectance $(R=0.42$ and $P<0.01$ for resistance at $120 \mathrm{~Hz}$ and $1 \mathrm{kHz}$ versus reflectance from 420 to $680 \mathrm{~nm}$ ). Thus, without astaxanthin in the diet, muscle colour and tissue integrity at $24 \mathrm{~h}$ deteriorated with the age of the fish.
\end{abstract}

\section{Introduction}

The Arctic charr, Salvelinus alpinus (L.), is a large salmon-like fish that can be commercially farmed with rapid growth in cold conditions (DFO 1991). The commercial importance of carotenoid colouration in salmonid muscle is widely appreciated in the aquaculture industry and by food retailers (Simpson 1982): intense colouration makes the product more attractive for many customers, but is relatively expensive to induce in captive stock by dietary supplementation. Carotenoid pigmentation may be measured objectively by colourimetry (Foss, Storebakken, Schiedt, Liaaen-Jensen, Austreng \& Streiff 1984; Skrede \& Storebakken 1986; King 1996), but this involves exposing several square centimetres of muscle; less destructive methods are required for routine monitoring of pigment accumulation during growth and for grading the finished product.

The present research was undertaken to determine if a relatively small-diameter fibre-optic probe capable of penetrating the skin of an intact fish with minimal damage could be used to measure internal carotenoid colouration of muscles. Another objective was to investigate light scattering from tissue microstructure as a source of error in measuring dissolved carotenoid pigment: when light scattering from microstructural sources such as precipitated sarcoplasmic proteins or shrunken myofibrils is high, the muscle appears pale and normal pigmentation from dissolved chromophores is obscured (Swatland 1995). Electrical impedance was used as a rapid method to assess the state of the muscle: in fish muscle post-mortem, cell membrane capacitance is lost and electrolytic resistance decreases, so that high capacitance and resistance indicate a high degree of cellular integrity (Jason \& Lees 1971; Kent \& Jason 1975). 


\section{Materials and methods}

\section{Fish}

Samples of fish muscle were obtained as a by-product of a proprietary experiment on the effects of dietary astaxanthin (Roche, Basel, Switzerland). Feeding levels were 0, 40, 80 and $120 \mathrm{mg} \mathrm{kg}^{-1}$ feed (reaching a level beyond that used commercially). The strategy for the study reported here was simply to use the end products of the commercial experiment as a population with a maximum range in colour.

Fish were raised at the Aquaculture Research Station, Alma, Ontario, Canada. The stock originated from a Labrador strain of Arctic charr which had been captive for four generations. Fish were spawned from October 1993 to February 1994 and were immature (14-18 months) at the start the experiment. None of the fish had previously received any feed to which astaxanthin had been added. Some fish were sampled on 3 April $1996(n=25)$. Feeding of diets with different astaxanthin levels commenced on 23 April 1996, after which groups of 60 fish (15 controls and 45 with astaxanthin added to their diet) were sampled on 1 May, 29 May, 26 June and 24 July 1996 (times of trials of $0,1,5,9$ and 13 weeks). The basic diet was a commercial feed with a pellet size of $\approx 2 \mathrm{~mm}$ (Zeigler Brothers, Gardners, PA, USA). Fish were reared indoors in 12 rectangular fibre-glass tanks $(2 \times 2 \mathrm{~m}$ top area, capacity $10^{3} \mathrm{~L}$ ). The feed composition was: herring fishmeal, 31\%; corn gluten meal, 20\%; wheat middling, $22 \%$; soybean meal, $13 \%$; fish oil, $12 \%$; vitamin premix, $1 \%$; and mineral premix, $1 \%$. The water flow rate per tank was $\approx 30 \mathrm{~L} \mathrm{~min}^{-1}$ at $8.5 \pm 0.5^{\circ} \mathrm{C}$. Belt feeders dispensed the feed continuously during daylight (12 h). A 12-h light cycle was alternated with a 12-h dark cycle without gradation between the cycles.

A specific growth rate (SGR) giving percentage body weight gain per day was calculated as:

$$
\mathrm{SGR}=\left[\left(\ln \mathrm{W}_{2}-\ln \mathrm{W}_{1}\right) /(\text { days })\right] \times 100
$$

where $W_{1}$ and $W_{2}$ are initial and final body weights, respectively. Fish were weighed every 4 weeks. Specific growth rate declined from 0.56 at $0-4$ weeks to 0.48 at $4-8$ weeks, 0.45 at $8-12$ weeks and 0.36 at $12-16$ weeks. Average weights (mean $\pm \mathrm{SD})$ were $668 \pm 4.23 \mathrm{~g}$ at 0 weeks, $782 \pm 13 \mathrm{~g}$ at 4 weeks, $894 \pm 19 \mathrm{~g}$ at 8 weeks and $1014 \pm 22 \mathrm{~g}$ at 12 weeks. No significant effects of astaxanthin level on growth rate were detected and these figures are presented as pooled data.

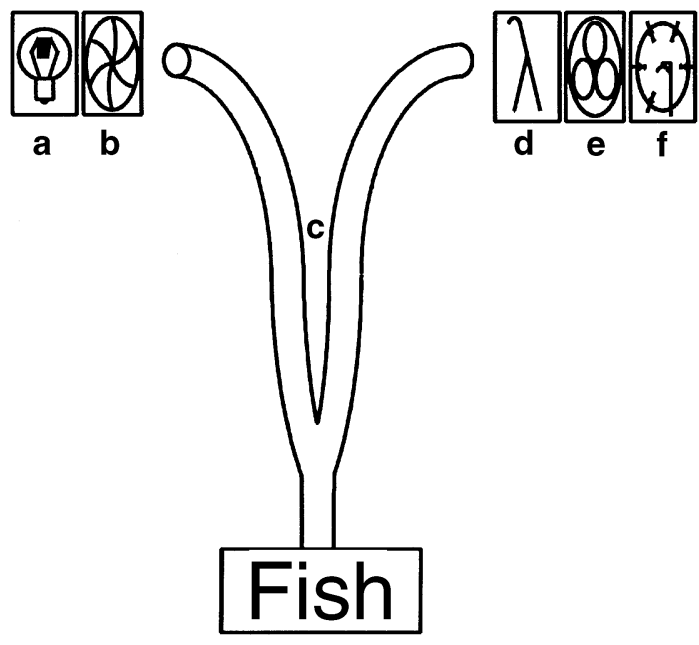

Figure 1 Apparatus used in the experiment: (a) halogen illuminator; (b) shutter; (c) bifurcated light guide; (d) grating monochromator; (e) stray-light filters; and (f) photomultiplier.

To obtain pigment scores, fish were separated into a small, aerated, plastic tank for randomized capture, and were stunned by cranial concussion, weighed and then killed by decapitation. After evisceration, a transverse steak $(\approx 1.5 \mathrm{~cm}$ thick) was taken posteriorly to the dorsal fin, and then washed and blotted dry. A subsample was taken dorso-laterally from the right side. The skin was removed and the muscle subsample was illuminated with two incandescent lamps (at $4800 \mathrm{~K}$ ) mounted in parabolic reflectors. The muscle subsample was observed on a white background and subjective colour scores were determined by two independent, trained evaluators using the Roche colour card for salmonids. The colour card is graded over eight colour intensities. Intermediate values ( \pm 0.5 units) were used for samples intermediate between two colour intensities. Thus, by using the mean of two evaluations, discrimination was in steps of 0.25 . Mean colour scores ranged from 0.5-5.0. The unused portions of the steaks were kept in plastic bags surrounded by ice for $\approx 24 \mathrm{~h}$ before being measured optically.

\section{Apparatus}

The apparatus used for fibre-optic measurements is shown in Fig. 1. A 12-V DC halogen lamp with a tungsten filament was powered at $11.99 \mathrm{~V}$ and $7.825 \mathrm{~A}$ from a stabilized DC power supply (6642 A, 
Hewlett-Packard, Palo Alto, CA, USA). The collimated output passed through a solenoidoperated shutter and was launched into one branch of a bifurcated light guide. The common trunk of the light guide was pushed $2-3 \mathrm{~mm}$ into the steaks. Internally scattered light was collected through the other branch of the light guide and passed through a grating monochromator (474345, Carl Zeiss, Oberkochen, Germany) containing stray light filters to remove higher-order harmonics (Zeiss 477215), and on to a side-window photomultiplier (HTVR928 with S-20 characteristics, Hamamatsu, Hamamatsu City, Japan). The bifurcated light guide (WW100, Guided-Wave, El Dorado Hills, CA, USA) had six optical fibres in the illuminating branch and one in the recording branch. In the common trunk of the light guide, the six illuminating fibres were arranged closely in a ring around the single recording fibre. For reference purposes, the large-diameter $(8 \mathrm{~mm})$ light guide was a type BLGS-1875-36-M (PBL Electro-Optics, New London, NH, USA) with the illuminating fibres and receiving fibres arranged in two back-to-back D-shaped bundles.

There is some uncertainty regarding the appropriate name for internal reflectance collected directly from a tissue by optical fibres. Sometimes internal reflectance is called interactance, but this has not achieved wide usage. For simplicity, the light collected from the samples is termed internal reflectance, although it is not the same as reflectance from the sample surface in air as measured under International Commission on Illumination (CIE) conditions.

Optical apparatus was operated via an IEEE-488 bus from a Hewlett-Packard 360 microcomputer programmed in BASIC using a Zeiss MPC controller. With the monochromator at $555 \mathrm{~nm}$, the high voltage and gain of the photomultiplier were set using $80 \%$ of its dynamic range. The shutter in front of the illuminator was used to correct for both ambient illumination (which was very low) and the dark current of the photomultiplier (which was subtracted from all measurements). The reflectance standard was a white opal glass disk under distilled water, using an adjustable clamp to find the point just above the glass surface that gave the highest return of light to the photometer. The monochromator was scanned from 400 to $700 \mathrm{~nm}$ in increments of $10 \mathrm{~nm}$ with a bandpass of $10 \mathrm{~nm}$ to find the reflectance maximum at each wavelength.

Electrical measurements were made using two stainless-steel needle electrodes (1 mm diameter,
$1 \mathrm{~cm}$ apart, and in contact with the muscle for a length of $11 \mathrm{~mm}$ ). The parallel electrodes were pushed into the fish steaks where the optical measurement had been taken, with the needles parallel to the vertebral axis of the muscle. Capacitance and resistance were measured with a digital LCR meter (Hewlett-Packard 4262 A) controlled via the IEEE 488 bus. Measurements were made at $120 \mathrm{~Hz}, 1 \mathrm{kHz}$ and $5 \mathrm{kHz}$, assuming resistance and capacitance to be in parallel (Gielen, Cruts, Albers, Boon, Wallinga-de Jonge \& Boom 1986). Whether or not reliable measurements of electrical impedance can be made with only two electrodes is somewhat contentious because of the risk of electrode polarization. The view taken here is that much of the classical information on the electrical properties of tissues has been (Burger \& van Dongen 1960; Geddes \& Baker 1967) and continues to be (Hart, Toll, Berner \& Bennett 1996) obtained with only two electrodes: the two electrode method also has many advantages in simplicity for an intended practical application.

In view of the size and complexity of the data set stored on hard disk, statistical analysis was undertaken directly on the main controller (HP 360) using software written in BASIC. Software was adapted from methods described by Steel \& Torrie (1980). For multiple regression analysis, the level for accepting up to three stepwise variables was $F=2$.

\section{Results}

\section{Effect of small-diameter probe}

Using the reference fibre-optic light guide with a relatively large diameter, the mean spectrum $(n=15)$ of non-pigmented mature muscle (line 1 in Fig. 2) seemed reasonable when compared with fibre-optic spectra of other food myosystems lacking strong pigmentation (Swatland 1995). Reflectance of low wavelengths was generally weaker than that of high wavelengths, and a haemoprotein Soret absorbance band was evident from 420 to $430 \mathrm{~nm}$, with secondary absorbance at $560 \mathrm{~nm}$. The extent to which haemoprotein shaping of the spectrum was determined by residual erythrocytes and myoglobin was not investigated.

However, when measured with the small-diameter probe, the shape of the fibre-optic reflectance spectrum was radically altered: the spectrum was relatively flat (line 2 in Fig. 2) with no shaping 

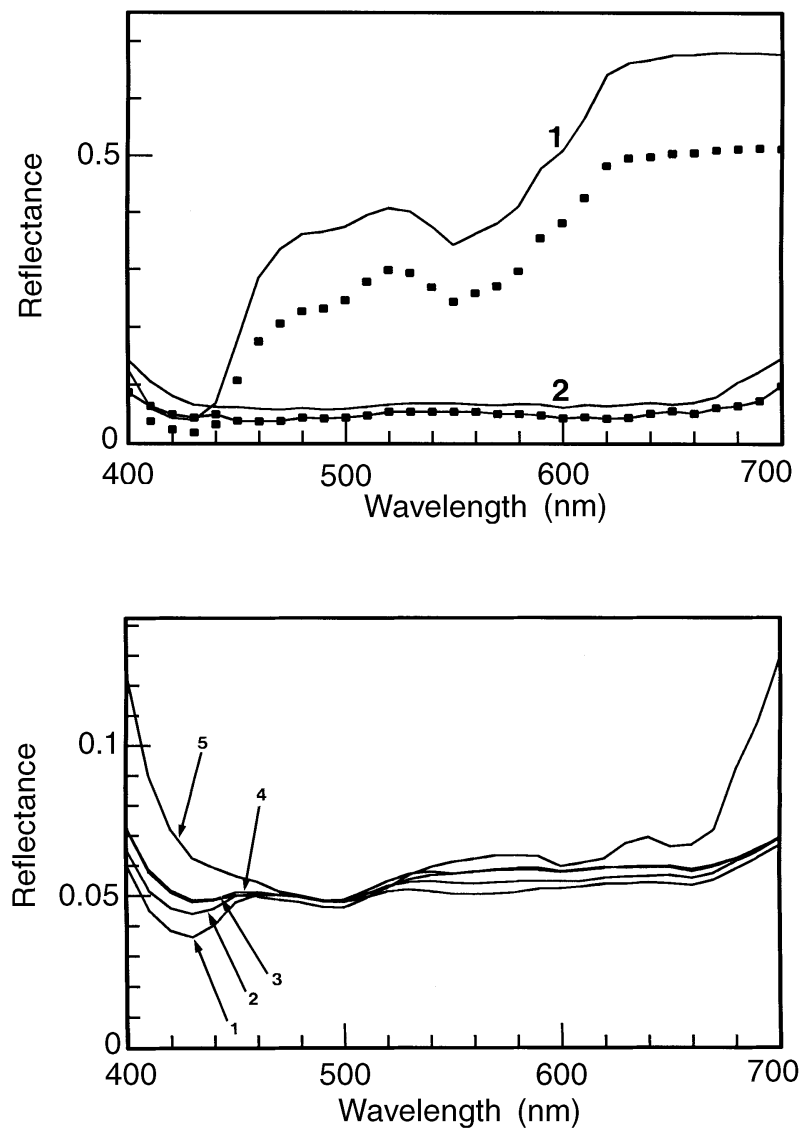

Figure 2 Comparison of reflectance spectra of mature, non-pigmented muscle obtained with large-diameter (line 1) and a small-diameter (line 2) light guides. Solid squares show standard deviations subtracted from means $(n=15)$. attributable to haemoproteins. Reflectance was high at 400 and $700 \mathrm{~nm}$.

\section{Effect of growth}

For controls without astaxanthin added to their diet, muscle reflectance measured with the smalldiameter probe increased as fish grew older and heavier (Fig. 3). With $n=85$ and a two-tailed test, the effect was significant $(P<0.01)$ from $400 \mathrm{~nm}$ $(r=0.68)$ to $440 \mathrm{~nm}(r=0.40)$ and from $530 \mathrm{~nm}$ $(r=0.30)$ to $700 \mathrm{~nm}(r=0.56)$. In agreement with this, subjective colour scores decreased (towards a lighter appearance) in fish without astaxanthin added to their diet $(r=-0.52 ; P<0.001$, twotailed; $n=85$ ).

\section{Prediction of subjective colour scores}

When data from all fish were pooled (controls plus those without astaxanthin added to their diet), the overall mean colour score was 1.67 (SD 0.90).
Starting at 0 weeks with subjective colour scores of $1.28 \pm 0.45$, fish without astaxanthin added to their diet by 12 weeks had colour scores of $0.82 \pm 0.41$, while the highest scores in fish with added astaxanthin reached $2.73 \pm 0.95$. With stepwise regression, colour scores were correlated with reflectance $(R=0.66 ; \quad P<0.01)$, using $500 \mathrm{~nm}(r=-0.21 ; F=13.3), 610 \mathrm{~nm}(r=0.61$; $F=157.9)$ and $520 \mathrm{~nm}(r=-0.27 ; F=20.5)$. The improvement by adding time on trial to the model was imperceptible ( $R$ increased from 0.657 to 0.662).

\section{Electrical properties}

Mean values for fish without astaxanthin added to their diet are shown in Table 1. Resistance at $24 \mathrm{~h}$ post-mortem decreased with the age of the fish, and fish with higher (darker) colour scores tended to have higher resistance. Relationships also were detected between electrical properties (mainly resistance) and fibre-optic reflectance (Table 2). 
Table 1 Simple correlations of electrical properties with subjective colour score and age in fish $(n=83)$ without astaxanthin added to their diet

\begin{tabular}{|c|c|c|}
\hline $\begin{array}{l}\text { Electrical property } \\
\text { (mean } \pm S D)\end{array}$ & $\begin{array}{l}\text { Correlation with } \\
\text { colour score }\end{array}$ & $\begin{array}{l}\text { Correlation } \\
\text { with age }\end{array}$ \\
\hline $\begin{array}{l}\text { Capacitance at } 120 \mathrm{~Hz} \\
\qquad(4.06 \mathrm{E}-7 \pm 1.37 \mathrm{E}-7 \mathrm{~F})\end{array}$ & $-0.22^{\star}$ & 0.12 \\
\hline $\begin{array}{l}\text { Resistance at } 120 \mathrm{~Hz} \\
(1026 \pm 273 \mathrm{~A})\end{array}$ & $0.36^{* *}$ & $-0.42^{* *}$ \\
\hline $\begin{array}{l}\text { Capacitance at } 1 \mathrm{kHz} \\
(2.6 \mathrm{E}-7 \pm 2.67 \mathrm{E}-7 \mathrm{~F})\end{array}$ & -0.11 & 0.19 \\
\hline $\begin{array}{l}\text { Resistance at } 1 \mathrm{kHz} \\
(769 \pm 240 \mathrm{~A})\end{array}$ & $0.27^{\star}$ & $-0.39^{* *}$ \\
\hline $\begin{array}{l}\text { Capacitance at } 10 \mathrm{kHz} \\
\qquad(1.36 \mathrm{E}-8 \pm 5.21 \mathrm{E}-9 \mathrm{~F})\end{array}$ & 0.17 & -0.10 \\
\hline $\begin{array}{l}\text { Resistance at } 10 \mathrm{kHz} \\
\qquad(476 \pm 90 \mathrm{~A})\end{array}$ & $0.40^{* *}$ & $-0.54^{\star \star}$ \\
\hline
\end{tabular}

Table 2 Multiple correlation coefficients $(P<0.01)$ of electrical properties with fibre-optic reflectance $(R)$ detected in fish $(n=83)$ without astaxanthin added to their diet

\begin{tabular}{lll}
\hline Electrical property & $\boldsymbol{R}$ & $\begin{array}{l}\text { Wavelengths } \\
\text { selected }\end{array}$ \\
\hline Resistance at $120 \mathrm{~Hz}$ & 0.42 & $420 \mathrm{~nm}$ \\
& & $680 \mathrm{~nm}$ \\
& & $470 \mathrm{~nm}$ \\
Resistance at $1 \mathrm{kHz}$ & 0.42 & $420 \mathrm{~nm}$ \\
& & $490 \mathrm{~nm}$ \\
& & $680 \mathrm{~nm}$ \\
Capacitance at $10 \mathrm{kHz}$ & 0.39 & $440 \mathrm{~nm}$ \\
& & $700 \mathrm{~nm}$ \\
& & $430 \mathrm{~nm}$ \\
Resistance at $10 \mathrm{kHz}$ & 0.36 & $400 \mathrm{~nm}$ \\
& & $470 \mathrm{~nm}$ \\
& & $560 \mathrm{~nm}$ \\
\hline
\end{tabular}

\section{Discussion}

Like many other food myosystems, the overall appearance of salmonid muscle may be produced by an interaction of many different factors, only one of which is the chemical state and concentration of carotenoid pigment (Simpson 1982). A key point found in the present study is that, as the fish without astaxanthin added to their diet grew older and heavier, their muscles became progressively paler in appearance and their post-mortem electrical characteristics indicative of cellular integrity (such as resistance at $10 \mathrm{kHz}$ in Table 1) tended to deteriorate. Thus, being deprived of added astaxanthin and the beneficial metabolic properties of carotenoids, the control fish perhaps may have been exhibiting signs of a nutritional myodegeneration. In other words, the identity of control and treatment groups gets confused because the deprivation of carotenoid pigments may have a more insidious effect than artificially inducing a high level.

For total quality management of muscle colouration in farmed Arctic charr, something more than simply adding an appropriate pigment to the diet is required. Information feedback measurements are needed as the fish are growing, together with quality-assurance measurements on the finished product: and the measurements must be rapid and relatively non-destructive, hence the use of fibreoptics and electrical impedance. Unfortunately, from the relative flatness of the reflectance spectra obtained with the small-diameter fibre-optic probe (Fig. 2), it was apparent that the relatively nondestructive small-diameter probe had a maximum sensitivity to light scattering and was not particularly sensitive to pigmentation. The reason was that the small-diameter dictated that illuminating and receiving optical fibres were close together, thus responding strongly to light scattering at the interface between optical fibres and muscle fibres: for maximum sensitivity to dissolved chromophores, it is necessary to force a long light path through the tissue by separating the illuminating and receiving optical fibres. Thus, when small-diameter fibre-optic probe data were used to predict colour scores in the overall population of fish ranging from zero to high levels of astaxanthin added to the diet, correlations were detected, but were not reliable enough for a practical application. It might be possible to improve the prediction of colour scores from fibre-optic data by using crossed polarizing filters on the probe tip, so that only light depolarized by scattering through a long light path is collected by the probe (Swatland 1997). Unfortunately, this method had not yet been invented when the experiments reported here were undertaken.

In summary, although unsuccessful in its immediate objective of providing a relatively non-destructive method to monitor pigment 
accumulation in farmed salmonids, some progress has been made. The results show that muscle colouration in fish is similar to that in other food myosystems: visual appearance of the myosystem is an interaction between pigment accumulation and light scattering from tissue microstructure, and it seems unwise to attempt quality management of the former without controlling or correcting for the latter. Electrical impedance methods, originally developed to monitor post-mortem freshness in cod (Jason \& Lees 1971), could be useful accessory measurements for quality-control management of muscle colour in farmed salmonids.

\section{Acknowledgments}

This research was supported by the Ontario Ministry of Agriculture, Food and Rural Affairs. Thanks to the staff of the Alma Aquaculture Research Station for maintenance and feeding of the fish.

\section{References}

Burger H.C. \& van Dongen R. (1960) Specific electric resistance of body tissues. Physics in Medicine and Biology 5, 431-447.

Department of Fisheries and Oceans (DFO) (1991) Arctic charr. Underwater World 31, 1-6.

Foss P., Storebakken T., Schiedt K., Liaaen-Jensen S., Austreng E. \& Streiff K. (1984) Carotenoids in diets for salmonids. I. Pigmentation of rainbow trout with the individual optical isomers of astaxanthin in comparison with canthaxanthin. Aquaculture 41 213-226.

Geddes L.A. \& Baker L.E. (1967) The specific resistance of biological material-a compendium of data for the biomedical engineer and physiologist. Medical and Biological Engineering 5, 271-293.

Gielen F.L.H., Cruts H.E.P, Albers B.A., Boon K.L., Wallingade Jonge W. \& Boom H.B.K. (1986) Model of electrical conductivity of skeletal muscle based on tissue structure. Medical and Biological Engineering 24, 34-40.

Hart F.X., Toll R.B., Berner N.J. \& Bennett N.H. (1996) The low-frequency dielectric properties of octopus arm measured in vivo. Physics in Medicine and Biology 41, 2043-2052.

Jason A.C. \& Lees A. (1971) Estimation of Fish Freshness by Dielectric Measurement. Torry Research Station, Department of Trade and Industry, Aberdeen.

Kent M. \& Jason A.C. (1975) Dielectric properties of foods in relation to interactions between water and substrate. In: Water Relations of Foods (ed. by R. B. Duckworth), pp. 211-231. Academic Press, New York, NY.

King T.L. (1996) Use of colorimetric analysis to estimate Salmonid flesh carotenoid content. Progressive Fish Culturist 58, 215-218.

Simpson K.L. (1982) Carotenoid pigments in seafood. In: Chemistry and Biochemistry of Marine Food Products (ed. by R. E. Martin, G. J. Flick, C. E. Hebard \& D. R. Ward), pp. 115-136. AVI Publishing Company, Westport, CT.

Skrede G. \& Storebakken T. (1986) Instrumental colour analysis of farmed and wild Atlantic salmon when raw, baked and smoked. Aquaculture 53, 279-286.

Steel R.G.D. \& Torrie J.H. (1980) Principles and Procedures of Statistics. A Biometrical Approach. McGraw-Hill, New York, NY.

Swatland H.J. (1995) On-line Evaluation of Meat. Technomic Publishing, Lancaster, PA.

Swatland H.J. (1997) Relationships between the backscatter of polarised light and the fibre-optic detection of connective tissue fluorescence in beef. Journal of the Science of Food and Agriculture 75, 45-49. 